\title{
OFICINAS DE APRENDIZAGEM NO ENSINO DE FÍSICA: UM ESTUDO DE CASO COM EXPERIÊNCIAS DE TERMODINÂMICA
}

\author{
LEARNING WORKSHOPS IN PHYSICS TEACHING: A CASE STUDY WITH EXPERIENCES IN \\ THERMODYNAMICS
}

TALLERES DE PRENDIZAJE EN LA ENSEÑANZA DE LA FÍSICA: UN ESTUDIO DE CASO CON EXPERIENCIAS EN TERMODINÂMICA

\section{Caio Araujo Cruz \\ iD 9}

Mestrando em Ensino de Ciências

e Matemática pelo Instituto

Federal do Ceará (IFCE)

caio.araujo.cruz@hotmail.com

\section{Maria Elizete Pereira Alencar Oliveira (iD) 9}

Mestranda em Ensino de Ciências e Matemática pelo Instituto Federal do Ceará (IFCE) maria.elizete.peteira67@aluno.ifce .edu.br

\section{Gilvandenys Leite Sales (iD) 9}

Doutor em Engenharia de Teleinformática pela Universidade Federal do Ceará (UFC) denyssales@ifce.edu.br

\section{Alisandra Cavalcante Fernandes de Almeida (iD) 9 \\ Doutora em Educação pela Pontifícia Universidade Católica de São Paulo (PUC-SP) alisandra.cavalcante@ifce.edu.br}

\begin{abstract}
Resumo
Apresenta-se a metodologia das Oficinas de Aprendizagem como alternativa para ensinar Física nas escolas. Essa metodologia valoriza os conhecimentos dos alunos e promove a aproximação à realidade, por meio da experimentação, com preparo para a vida cotidiana e lidar com situações que envolvam conhecimentos de Física. Baseia-se no conceito da aprendizagem significativa de David Ausubel (1918 - 2008) como alternativa para obter mudança na educação de alunos do Ensino Médio. O estudo de caso, realizado em 2018, mostra a diferença na aprendizagem dos jovens participantes da Oficina de Aprendizagem de Física (grupo experimental) e dos que não participaram (grupo de controle), por meio do comparativo entre duas turmas do Ensino Médio do IFCE. Como resultado, notou-se melhora na compreensão dos conceitos apresentados. Espera-se, com este trabalho, evidenciar a diferença na aprendizagem dos alunos com a metodologia e trazer melhoria para o ensino e a aprendizagem de Física no Ensino Médio.
\end{abstract}

Palavras-chave: Oficinas de aprendizagem. Aprendizagem significativa. Termodinâmica.

Recebido em: 22 de junho de 2021. Aprovado em: 1 de outubro de 2021.

Como citar esse artigo (ABNT):

CRUZ, Caio Araujo et al. Oficinas de aprendizagem no ensino de física: um estudo de caso com experiências de termodinâmica. Revista Prática Docente, v. 6, n. 3, e082, 2021. http://doi.org/10.23926/RPD.2021.v6.n3.e082.id1236 


\begin{abstract}
The methodology of the Learning Workshops is presented as an alternative to teaching Physics in schools. This methodology values the students' knowledge and promotes the approach to reality, through experimentation, with preparation for everyday life and to deal with situations involving knowledge of Physics. It is based on David Ausubel's (1918 - 2008) concept of meaningful learning as an alternative to seek a change in the education of high school students. The case study carried out in 2018 shows the difference in the learning of young participants in the Physics Learning Workshop (experimental group) and those who did not (control group), by comparing two high school classes at IFCE. As a result, there was an improvement in the understanding of the concepts presented. It is expected, with this work, to show the difference in student learning with the methodology and bring improvement to the teaching and learning of Physics in High School.
\end{abstract}

Keywords: Learning Workshops. Meaningful Learning. Thermodynamics.

\section{Resumen}

La metodología de los Talleres de Aprendizaje se presenta como una alternativa a la enseñanza de la Física en las escuelas. Esta metodología valora los conocimientos de los estudiantes y promueve el acercamiento a la realidad, a través de la experimentación, con la preparación para la vida cotidiana y para afrontar situaciones que involucran conocimientos de Física. Se basa en el concepto de aprendizaje significativo de David Ausubel (1918 - 2008) como alternativa para buscar un cambio en la educación de los estudiantes de secundaria. El caso de estudio realizado en 2018 muestra la diferencia en el aprendizaje de los jóvenes participantes en el Taller de Aprendizaje de Física (grupo experimental) y los que no lo hicieron (grupo de control), al comparar dos clases de bachillerato en IFCE. Como resultado, hubo una mejora en la comprensión de los conceptos presentados. Se espera, con este trabajo, mostrar la diferencia en el aprendizaje de los estudiantes con la metodología y aportar una mejora en la enseñanza y el aprendizaje de la Física en el escuela secundaria.

Palabras clave: Talleres de aprendizaje. Aprendizaje significativas. Termodinámica. 


\section{INTRODUÇÃ̃o}

No cotidiano, é possível experienciar situações que envolvem e podem ser explicadas por variados conceitos físicos, desde abrir uma porta, até acender uma lâmpada, ou ferver um bule d'água para o preparo de um chá. Dessa forma, o cotidiano pode tornar-se especial "laboratório" físico, no qual, constantemente, é possível testar e observar situações que envolvam a Física.

Dessa forma, a aprendizagem dos conceitos de Física pode estar ligada diretamente com as situações cotidianas, nas quais já são conhecidos os efeitos e pode-se atestar os acontecimentos e resultados esperados. Entretanto, é discutido, principalmente nas obras do autor Marco Antônio Moreira (2000; 2010; 2018), que o ensino de Física tem sido abordado sob a ótica da metodologia tradicional.

Esse problema, que vem desde a colonização do continente e perdura até hoje, existe por vários fatores, como a estrutura política; a desigualdade social; a falta de uma cultura que valorize a Educação; a formação de professores; e a falta de estrutura em muitas escolas; aspectos amplamente discutidos por Schwartzman e Brock (2005).

O ensino de Física, por exemplo, ainda segue o modelo tradicional, em que é utilizada apenas a exposição de conceitos durante a aula. O professor coloca-se no papel de detentor do conhecimento e cabe aos alunos absorverem o que lhes é passado, de modo que são induzidos a reproduzir, em avaliações, os conceitos idealizados contidos nos livros didáticos. Os estudantes, assim, não se sentem instigados a aprender, muitas vezes, por não conseguirem perceber a relação entre os conteúdos ensinados e a sua utilização no cotidiano.

O ensino de Física tem-se realizado frequentemente mediante a apresentação de conceitos, leis e fórmulas, de forma desarticulada, distanciados do mundo vivido pelos alunos e professores e não só, mas também por isso, vazios de significado. (BRASIL, 2000, p. 22).

Nesse modelo de ensino, o professor "Insiste na solução de exercícios repetitivos, pretendendo que o aprendizado ocorra pela automatização ou memorização e não pela construção do conhecimento através das competências adquiridas” (BRASIL, 2000, p. 22).

Já segundo a Base Nacional Comum Curricular (BNCC) do Ensino Médio, observa-se pequena mudança nos objetivos a serem alcançados nessa etapa da formação básica. Segundo Brasil (2018, p.469), “as áreas do conhecimento têm por finalidade integrar dois ou mais componentes do currículo, para melhor compreender a complexa realidade e atuar nela". 
A BNCC também aponta que a mudança do currículo, que hoje utiliza o conceito de desenvolvimento de competências, incentiva o desenvolvimento no "saber" dos alunos, mas, principalmente, no "saber fazer" (BRASIL, 2018).

Além disso, na atual conjuntura, os professores das redes pública e particular são alocados para ministrar uma grande quantidade de aulas e em turmas diferentes, chegando a trabalhar por três turnos no dia, principalmente na rede privada. Conforme aponta Pereira et al. (2013, p.233),

os professores formam uma categoria profissional especialmente exposta a rotina de trabalho de grande desgaste psicológico devido a fatores como carga horária excessiva, baixos salários, condições degradantes de trabalho e má organização do sistema educacional e das escolas.

Com isso, é menor a disponibilidade de tempo, há menos motivação, e o contexto é desfavorável aos professores que pretendam adotar novas metodologias de ensino e melhorar o aprendizado do aluno. É também de conhecimento comum, no Brasil, a falta de investimento na Educação, por parte do governo. Conforme aponta a Organização para a Cooperação e Desenvolvimento Econômico (OCDE, 2017, p. 2),

Nos anos finais do ensino fundamental e no médio a situação não é diferente. O Brasil gasta anualmente a mesma soma de US\$ 3,8 mil por aluno desses ciclos e também está entre os últimos na lista dos 39 países que forneceram dados a respeito. A média nos países da OCDE nos últimos anos do ensino fundamental e no médio é de US\$ 10,5 mil por aluno, o que representa $176 \%$ a mais do que o Brasil.

Assim, os professores encontram diversas barreiras, para oferecer uma aula diferente, por falta de recursos, tempo, estrutura, formação. Grande parte das escolas públicas não dispõe de laboratórios de ciências, ou estão com seus laboratórios abandonados, por não terem recursos para mantê-los; assim, a maioria dos professores acaba atrelada ao modelo tradicional de aulas expositivas, apenas escrevendo o conteúdo na lousa e usando livros didáticos para praticar seu trabalho docente.

Segundo Berezuk e Inada (2010, p.209),

pode-se afirmar que as escolas públicas possuem maior dificuldade para a realização de aulas laboratoriais pelas condições precárias de uso dos laboratórios causadas pela falta de investimento nesses estabelecimentos, ocasionando falta de equipamentos e materiais, falta de recursos para a manutenção de equipamentos e de um espaço físico apropriado para ser utilizado como laboratório didático.

Consideradas essas problemáticas, é necessário pensar em uma mudança na metodologia de ensino e planejar mais investimentos na Educação e no treinamento dos professores, para que, assim, os alunos possam ter acesso a uma Educação de qualidade, e a uma estrutura que favoreça a aprendizagem, para que, com novas metodologias de ensino, 
possam se sentir incluídos no processo de ensino e aprendizagem e, assim, enxergar a Física de forma concreta e conectada com a própria realidade.

Além disso, essas mudanças vão levar os professores a se sentirem valorizados, no exercício de sua profissão, e motivados a construir um futuro melhor para o país e os alunos, por meio da Educação. "É preciso rediscutir qual Física ensinar para possibilitar uma melhor compreensão do mundo e uma formação para a cidadania mais adequada.” (BRASIL, 2000, p. 23).

Assim, as Oficinas de Aprendizagem de Física (OAFs) são apresentadas, neste artigo, como uma alternativa metodológica que pode levar aos alunos uma experiência de desenvolverem suas habilidades cognitivas, utilizando seus subsunçores, segundo conceito definido por David Ausubel (1968), e ainda contribuir diretamente para a melhora nas notas de avaliação dos estudantes. Além disso, podem ser utilizados materiais de baixo custo e, com isso, reduzir o investimento necessário para realizar essa atividade. As oficinas surgem, ainda, como uma possibilidade real, dentro das escolas, e podem se tornar objeto de mudança para a realidade atual do ensino de Física no Brasil.

\section{REFERENCIAL TEÓRICO}

A metodologia das OAFs valoriza os conhecimentos dos alunos e promove a aproximação à realidade, por meio da experimentação, com preparo para a vida cotidiana e lidar com situações que envolvam conhecimentos de Física.

\subsection{AS OFICINAS DE APRENDIZAGEM}

As Oficinas de Aprendizagem foram desenvolvidas no Brasil pela educadora Márcia Rigon (28 de dezembro de 1950 - 13 de junho de 2013). Formada em Letras e especialista em Linguística e Filologia, iniciou seu projeto na cidade de Montenegro/RS motivada pela necessidade dos estudantes e cobrança dos pais de alunos por uma educação inovadora.

Essa nova escola saiu do papel em fins de 1991, por meio da necessidade que um executivo de uma empresa de minha cidade sentiu de ter uma escola com um projeto moderno, para manter os funcionários na cidade, visto que a maioria de seus gerentes não ficava na cidade por falta de uma escola diferente para seus filhos. Como eu tinha o projeto da nova escola em mente, fizemos uma parceria e nasceu o Colégio Montenegro. (RIGON, 2010, p. 13).

Em 2005, o Colégio Serviço Social da Indústria (Sesi), em Pato Branco/PR, adotou a metodologia das Oficinas de Aprendizagem de Rigon, tornando-se talvez a única escola 
brasileira a empregar essa metodologia como seu carro-chefe e seu diferencial para a aprendizagem dos alunos.

O Instituto Federal de Educação, Ciência e Tecnologia do Ceará (IFCE), por sua vez, oferta Oficinas de Aprendizagem voltadas à Física e Matemática para alunos de escolas públicas da comunidade de Fortaleza, por meio do projeto Oficinas de Ciências, Arte e Tecnologia (Ciartec), sob coordenação do Prof. Gilvandenys Leite Sales. Segundo Sales e Barbosa (2005, p. 4): “[...] as Oficinas de Física poderão colaborar para dar um novo rumo ao ensino da física, tida como uma disciplina difícil [...]”.

As Oficinas de Aprendizagem objetivam valorizar o papel do aluno na sala de aula, ao torná-lo protagonista da própria aprendizagem, enquanto o professor ocupa a função de mediador. Os alunos têm, assim, a oportunidade de trabalhar em equipe, para pesquisar sobre o conteúdo proposto e resolver os problemas apresentados pelo professor de forma autônoma, desenvolvendo, então, suas habilidades cognitivas para compreender o problema e encontrar a solução.

As Oficinas de Aprendizagem foram desenvolvidas para dar aos alunos e aos professores a oportunidade de trabalhar conhecimentos, valores, habilidades, talentos, dons e competências de forma significativa, transdisciplinar, interseriada, abrindo espaço para uma nova forma de aprender que investiga, trabalha, aprofunda, olha necessidades, impulsiona talentos e atende às habilidades individuais dos alunos, privilegiando as melhores maneiras de aprender [...]. (RIGON, 2010, p. 40).

Além disso, dentro de uma OAF, é possível trabalhar assuntos contextualizados e interligados com outros conhecimentos, assim atendendo às necessidades de mudança que a disciplina de Física precisa para facilitar a aprendizagem dos alunos. Ao utilizar as OAFs, o docente traz uma abordagem concreta dos conceitos da Física, visto que o aluno tem a oportunidade de fazer o experimento e construir um conhecimento genuíno, que o levará à própria conclusão sobre os efeitos do experimento. Além disso, com essa abordagem, o aluno passa a perceber a relação dos conceitos da Física com o seu cotidiano.

\subsection{OFICINAS COMO MEIO PARA PROPORCIONAR UMA APRENDIZAGEM SIGNIFICATIVA}

As OAFs proporcionam, dentro da sala de aula, a possibilidade de realizar uma aprendizagem significativa, porque os alunos utilizam seus subsunçores, definidos por Moreira (2010, p. 2), conforme a teoria de David Ausubel, como:

subsunçor é o nome que se dá a um conhecimento específico, existente na estrutura de conhecimentos do indivíduo, que permite dar significado a um novo conhecimento que lhe é apresentado ou por ele descoberto. Tanto por recepção como por descobrimento, a atribuição de significados a novos conhecimentos depende da 
existência de conhecimentos prévios especificamente relevantes e da interação com eles no processo de aprendizagem.

Com essa abordagem, os alunos participantes de OAFs passam a se sentir protagonistas da própria aprendizagem, pois têm seus conhecimentos prévios, cotidianos e de sua vivência, valorizados em sala de aula. Em geral, os estudantes passam pelo período escolar aprendendo a partir de um modelo mecânico de ensino, que é definido, de acordo com Moreira (2010, p. 12), como:

aprendizagem mecânica, aquela praticamente sem significado, puramente memorística, que serve para as provas e é esquecida, apagada, logo após. Em linguagem coloquial, a aprendizagem mecânica é a conhecida decoreba, tão utilizada pelos alunos e tão incentivada na escola.

Por esse motivo, muitos conceitos ensinados são esquecidos, ou nem mesmo são apreendidos durante as aulas; contudo, se a aprendizagem for significativa, a maior parte dos alunos terá facilidade de retomar os conteúdos repassados, como exemplifica David Ausubel (apud MOREIRA, 2010, p. 4):

\begin{abstract}
No caso das Leis de Conservação, um aluno que tivesse adquirido esse conceito significativamente mas que depois de sair da escola, ou da faculdade, passasse muito tempo sem envolver-se com temas de Física provavelmente continuaria sabendo que essa é uma ideia central em Física, mas talvez não lembrasse exatamente quais grandezas físicas se conservam e quais não se conservam, e muito menos o formalismo de uma determinada lei de conservação. Mas, uma vez que a aprendizagem tivesse sido significativa, e esse sujeito retomasse estudos de Física, provavelmente não teria muita dificuldade em "resgatar", "reativar" ou "reaprender" o subsunçor Leis de Conservação (grifos no original).
\end{abstract}

O uso de OAFs para proporcionar uma aprendizagem significativa, segundo Silva (2020, p.2), “descreve o comportamento teórico do processo de aprendizagem cognitiva, a partir do raciocínio dedutivo do sujeito, baseado em seu conhecimento prévio". Portanto, mostra-se de grande importância, para que o aluno possa utilizar seus subsunçores para a construção do novo conhecimento proposto durante a oficina, e também estruturas para a formação de novos subsunçores para auxiliá-lo em experiências futuras de aprendizagem, seja na carreira acadêmica ou mesmo em cursos de preparação e especialização.

As OAFs também terão o papel de auxiliar o aluno a conseguir atribuir real significado ao conteúdo aprendido durante a aula, em sua vida; compreender a influência de tal conteúdo em seu cotidiano; e não ficar restrito novamente ao método decorativo, em que apenas absorve o conteúdo para reproduzi-lo em testes futuros. Com a utilização das OAFs, é esperado, ainda, que o rendimento escolar cresça significativamente, pois os alunos passam a ter uma aula diferenciada; sentem-se motivados a aprender; e valorizados com o uso dos seus subsunçores; além de ver situações corriqueiras representadas em sala de aula, mas com o rigor científico. 


\section{Metodologia}

Neste trabalho, são reproduzidos os resultados de um estudo de caso, que é definido, por Gil (2002, p.54), como o "[...] estudo profundo e exaustivo de um ou poucos objetos, de maneira que permita seu amplo e detalhado conhecimento, tarefa praticamente impossível mediante outros delineamentos já considerados”.

No estudo de caso aqui descrito, foi investigado o rendimento de duas turmas do terceiro período (P3) do IFCE. O grupo experimental foi composto por 11 alunos da turma do Curso Técnico em Mecânica Industrial, que participou da OAF. O grupo controle, com 12 alunos, abrangeu a turma do Curso Técnico em Edificações. Ambas as turmas foram escolhidas por terem visto o conteúdo abordado na OAF, previamente, em seus respectivos cursos; dessa forma, possuíam os recursos necessários e os subsunçores construídos previamente para que pudessem responder ao questionário proposto. A OAF foi escolhida por se tratar de uma Oficina anteriormente testada e estruturada, de forma a garantir melhor execução dentro da pesquisa.

A OAF de Termodinâmica foi dividida em três momentos: Primeiramente, o professor apresentou o conteúdo de forma teórica, para inserir os alunos no contexto da aula; contextualizar com o cotidiano e a realidade dos estudantes; no segundo momento, o professor dividiu os estudantes em grupos para que realizassem as experiências, nesse caso, em Termodinâmica. Os alunos desenvolveram os experimentos com base no conteúdo mostrado e, por último, no terceiro momento, responderam aos questionários propostos pelo professor para avaliar o aprendizado.

Nessa oficina, foram trabalhados três conceitos do conteúdo de Termodinâmica diferença de pressão, empuxo e dilatação térmica. A Oficina foi realizada da forma a seguir explicitada.

\section{Definição dos conceitos}

Primeiramente, cada conceito a ser apresentado na Oficina teve sua definição teórica, para facilitar seu emprego no experimento. O conceito de diferença de pressão é uma aplicação do Princípio de Pascal, enunciado em 1652 pelo físico Blaise Pascal (1623-1662), e diz que: “Uma variação da pressão aplicada a um fluido incompressível contido em um recipiente é transmitida integralmente a todas as partes do fluido e às paredes do recipiente" (HALLIDAY; RESNICK; WALKER, 2009, p. 64). 
Dentro da Oficina, esse conceito foi utilizado quando os alunos realizaram a experiência com uma vela dentro do copo. Após a vela apagar-se, a pressão dentro do copo diminuiu e a pressão atmosférica empurrou a água, que estava fora, para dentro do copo.

O segundo conceito, o empuxo, que faz parte do Princípio de Arquimedes, foi enunciado pelo matemático grego Arquimedes (282-212 a.C.), e diz que:

Quando um corpo está total ou parcialmente submerso em um fluido uma força de empuxo exercida pelo fluido age sobre o corpo. A força é dirigida para cima e tem um módulo igual ao peso do fluido deslocado pelo corpo. (HALLIDAY; RESNICK; WALKER, 2009, p. 66).

Esse conceito também foi usado quando os alunos realizaram a experiência com a vela dentro do copo. Após a água entrar no copo, a vela elevou-se um pouco, mostrando que a água exerce força sobre ela, ou seja, o empuxo.

O conceito de expansão dos materiais e dos fluidos é propriedade intrínseca a todos os materiais, que têm a capacidade de se expandir ou se contrair, quando é colocado ou retirado calor deles; essa propriedade depende de alguns fatores, e o mais importante é o coeficiente de dilatação, que é específico para cada material diferente.

Os alunos usaram esse conceito dentro da oficina, quando realizaram o experimento com papel alumínio e papel branco, pois puderam observar que um material dilata mais do que o outro, quando é colocada energia térmica sobre eles.

\subsection{REALIZAÇÃO DOS EXPERIMENTOS}

Após a definição correta dos conceitos, os alunos foram divididos em grupos de quatro ou cinco componentes, para realizar os experimentos em conjunto; interagir entre si; discutir; e entender como os conceitos explicados seriam então utilizados.

No primeiro experimento, fora empregados os seguintes materiais: Papel branco; Papel alumínio; Pregadores; Vela; Fósforos; Tesoura; Cola (Figura 1).

Figura 1 - Materiais da experiência 1

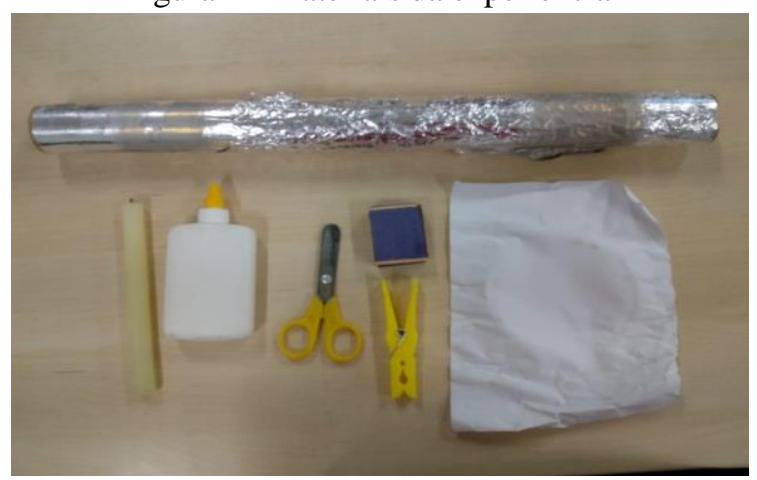

Fonte: Das atividades realizadas. 
Os alunos cortaram um pequeno pedaço de papel alumínio e um pedaço, do mesmo tamanho, de papel branco; depois, colaram os dois pedaços, deixando o papel alumínio por baixo do papel branco. Então, acenderam a vela e seguraram os papéis colados com o auxílio do pregador, para evitar que se queimassem. Conforme os papéis próximos à vela foram esquentando, os alunos perceberam que começaram a se curvar para cima, pois o papel branco dilatou menos do que o papel alumínio, e assim puxou o conjunto, por causa da cola que unia ambos os materiais.

O segundo experimento foi realizado com os seguintes materiais: Garrafa PET; Balões; Vela; Fósforo (Figura 2).

Figura 2 - Materiais da experiência 2

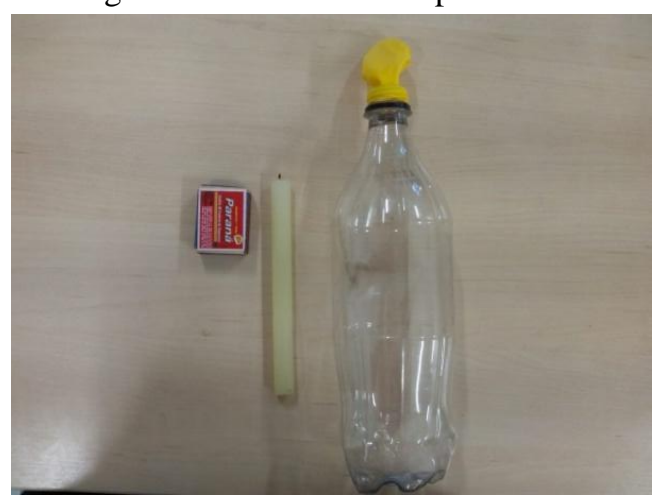

Fonte: Das atividades realizadas.

Os alunos colocaram o balão na boca da garrafa PET destampada; depois, esquentaram o fundo da garrafa usando a vela, com cuidado, para não derreter a garrafa. Após algum tempo, o balão começou a se encher sozinho; dessa forma, os alunos perceberam que os gases também sofrem o efeito da dilatação térmica, e, por isso, se expandem para dentro do balão.

O terceiro experimento precisou dos seguintes materiais: Copo; Pires; Vela; Fósforos; Água (Figura 3).

Figura 3 - Materiais da experiência 3

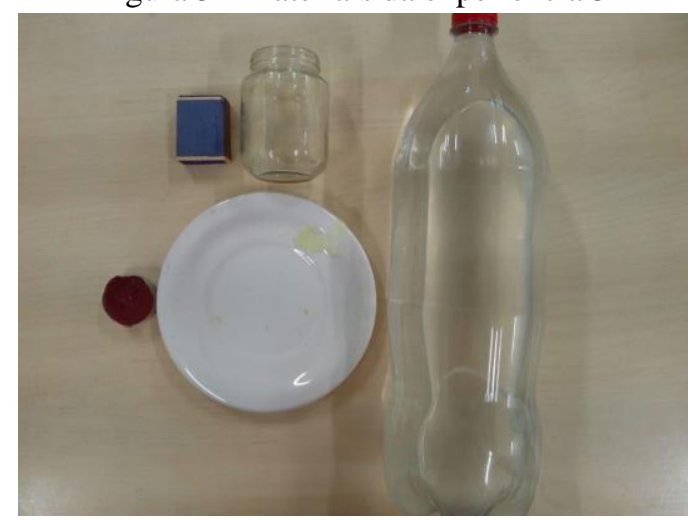

Fonte: Das atividades realizadas. 
Os alunos colocaram a vela no pires e um pouco d'água em sua superfície, sem deixar a vela submergir e nem flutuar; depois, acenderam a vela e colocaram o copo de cabeça para baixo, com a vela dentro do copo. Alguns segundos depois, a vela se apagou, provocando uma diferença de pressão dentro do copo; assim, a pressão externa empurrou a água, que estava fora, para dentro do copo, fazendo com que a vela flutuasse sobre a água. Os alunos perceberam, assim, os efeitos da diferença de pressão e do empuxo dentro do experimento.

\subsection{RESPONDER AO QUESTIONÁRIO}

Os estudantes, depois de realizados os experimentos, responderam às questões propostas pelo professor para fixar o conteúdo visto e para que o aprendizado dos alunos dentro da oficina de Física fosse avaliado.

Para esta pesquisa, foram escolhidas as questões apresentadas no Apêndice A, para avaliar os alunos após a oficina.

\section{DisCuSSÃo E ANÁLISE DE RESULTADOS}

Realizada a oficina, os alunos responderam, então, ao questionário proposto (Apêndice A) para que, assim, o professor fizesse a coleta de dados.

O grupo controle (turma A) e o grupo experimental (turma B) responderam ao questionário de forma discursiva, para ser possível analisar possíveis confusões em relação aos conceitos envolvidos nas experiências e questões.

Os gráficos apresentados nas Figuras 4 e 5 mostram o rendimento das turmas em cada questão apresentada no questionário, com os acertos; acertos parciais; e os erros das duas turmas.

Figura 4 - Rendimento da turma A

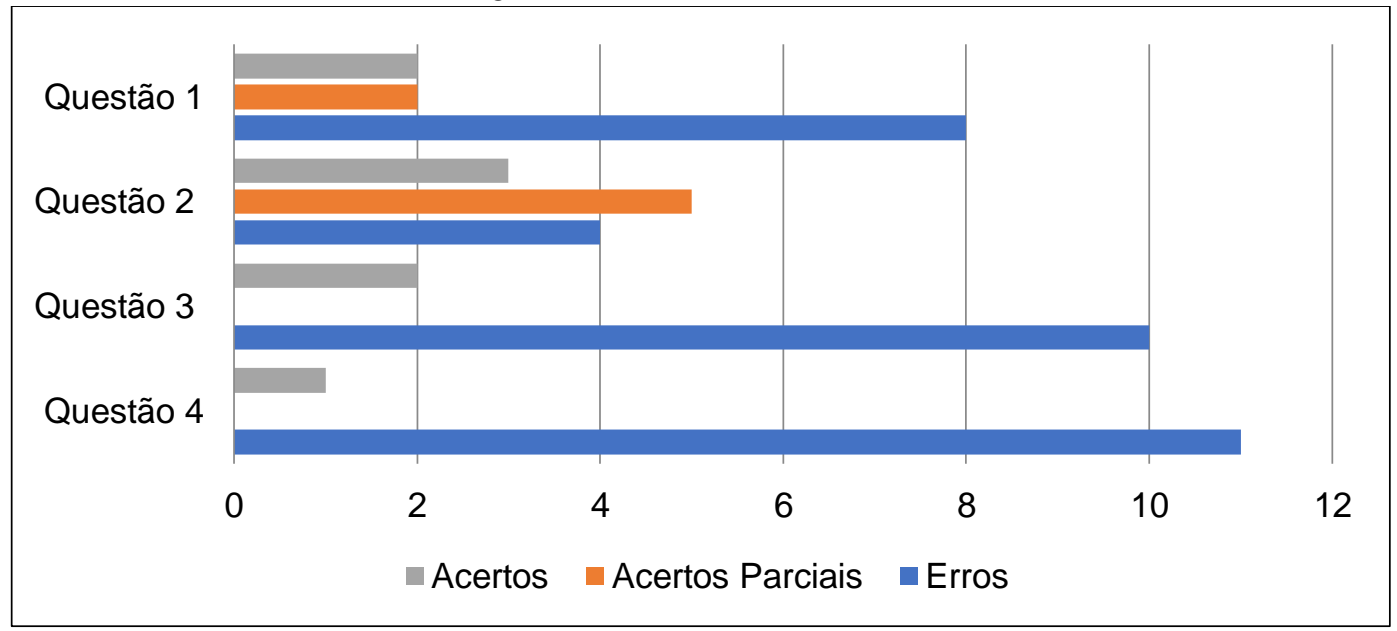

Fonte: Questionário proposto (Apêndice A). 
Figura 5 - Rendimento da turma B

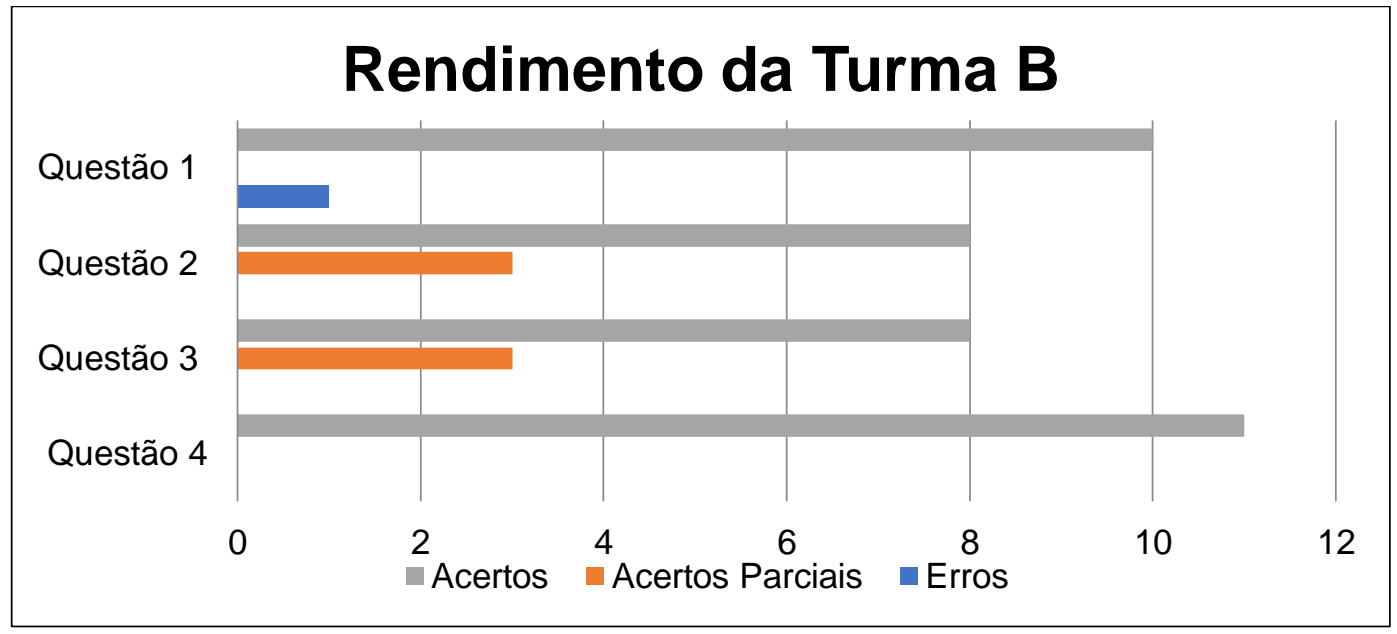

Fonte: Questionário proposto (Apêndice A).

Na primeira questão, segundo a análise dos gráficos, uma parcela maior da turma experimental B compreendeu corretamente os fenômenos que causam a dilatação dos corpos; já entre a turma A, de controle, que não participou da atividade, grande parte não soube, ou não se lembrou completamente, quais fenômenos estavam envolvidos na dilatação dos corpos.

Foi verificado que os alunos da turma A e os alunos da turma B, que erraram a questão, associaram a dilatação dos corpos apenas à temperatura e sua variação, não atentando ao fato de que a causa da dilatação dos corpos é, na verdade, o grau de agitação das moléculas, que aumenta ou diminui.

Ao analisar a segunda questão, observou-se que a turma B teve melhor compreensão do que é necessário para que aconteça a dilatação ou contração dos corpos. Já na turma A, percebeu-se certa confusão quanto a quais grandezas estão envolvidas diretamente nos efeitos de dilatação e contração.

Os alunos da turma $\mathrm{A}$, que erraram ou acertaram parcialmente, não consideraram o coeficiente de dilatação como uma grandeza necessária para que ocorresse a dilatação dos corpos, assim, deixaram de levar em conta parte importante dos conceitos de dilatação e contração térmicas.

Na terceira questão, notou-se, com a análise dos gráficos, que, na turma A, grande parte dos alunos não percebeu qual grandeza é responsável pela diferente dilatação nos diversos corpos. Entretanto, na turma B, os alunos tiveram a oportunidade de perceber, durante a experiência, que materiais diferentes têm dilatação diferente, o que se refletiu diretamente nas respostas obtidas. 
Os erros e acertos parciais deram-se pelo fato de os alunos das turmas A e B considerarem responsáveis pela dilatação diferente em corpos diferentes apenas os componentes que constituem os materiais (estruturas moleculares, densidade, rigidez) e não os diferentes coeficientes de dilatação. Alguns alunos da turma A responderam que não sabiam, mostrando esquecimento, ou, até mesmo, o não aprendizado desse conteúdo.

Observando os dados da quarta questão, foi possível perceber que, conforme mostram os gráficos, a turma B conseguiu relacionar o conceito trabalhado na experiência, o empuxo, com as situações cotidianas em que esse conceito é aplicado. Por outro lado, na turma A, percebeu-se que houve dificuldade em relacionar o conceito aprendido em sala de aula com a situação vivida no cotidiano.

Os erros e acertos parciais de ambas as turmas se deram porque os alunos não conseguiram relacionar corretamente o conceito ensinado na aula e uma situação cotidiana. Além disso, alguns alunos também relacionaram o empuxo à densidade da água e do corpo da pessoa.

\section{CONSIDERAÇõES FINAIS}

Com base nos resultados obtidos na pesquisa, percebeu-se que as OAFs se mostram eficazes para a aprendizagem dos alunos, tendo em vista que, quando o ensino é feito da forma tradicional, os estudantes têm uma aprendizagem vaga e que se perde em pouco tempo. Não é oferecida, aos estudantes das escolas que utilizam uma pedagogia tradicional, uma aprendizagem significativa, que poderia formar um aluno melhor preparado para a obtenção de futuros conhecimentos e para lidar com situações do cotidiano.

Mostra-se, também, que, com a utilização das OAFs, os alunos conseguem ter uma compreensão mais ampla sobre a parte conceitual da Física, além de visualizá-la envolvida nas situações corriqueiras e comuns a todos. Também é possível notar que há maior interação entre os alunos, durante as OAFs, incentivando, assim, o trabalho em equipe para, dessa forma, formar pessoas mais preparadas para um bom convívio em sociedade.

Além disso, conclui-se que é necessário discutir qual Física deve ser ensinada aos alunos; se deve ser ensinada apenas para que os alunos passem em provas e vestibulares ou para a vida fora das escolas; para formar cidadãos capazes de lidar com as situações do cotidiano de forma correta; e conseguir relacionar conceitos físicos à realidade vivenciada. 
É importante frisar que as OAFs não substituem completamente a metodologia de ensino, tendo em vista que alguns conteúdos exigem firme embasamento teórico, além do fato de que certas áreas da Física são de difícil experimentação.

Também é possível concluir que as OAFs podem ser atribuídas a outras áreas de conhecimento da Física e não apenas à área de Termodinâmica, dando, assim, continuidade aos objetivos deste trabalho de mostrar que há evidente melhora na aprendizagem dos alunos por meio dessa alternativa metodológica.

\section{REFERÊNCIAS}

BEREZUK, Paulo Augusto; INADA. Paulo. Avaliação dos laboratórios de ciências e biologia das escolas públicas e particulares de Maringá, estado do Paraná. Acta Scientiarum. Human and Social Sciences. Maringá, v. 32, n. 2, p. 207-215, 2010.

BRASIL, Ministério da Educação. Parâmetros curriculares nacionais: Ensino médio. Brasília, 2000.

BRASIL, Ministério da Educação. Base nacional comum curricular. Brasília, 2018.

BROCK, Colin; SCHWARTZMAN, Simon. Os desafios da educação no Brasil. Rio de Janeiro: Nova Fronteira, 2005.

GIL, Antonio Carlos. Como elaborar projetos de pesquisa. 4. ed. São Paulo, 2002.

HALLIDAY, David; RESNICK, Robert; WALKER, Jearl. Fundamentos de física. v. $2,8$. ed. Rio de Janeiro: LTC, 2009.

MOREIRA, Marco Antonio. Ensino de física no Brasil: Retrospectiva e perspectivas. Revista Brasileira de Ensino de Física, v. 22, n. 1, Porto Alegre, 2000.

MOREIRA, Marco Antonio. O que é afinal aprendizagem significativa? Porto Alegre, 2010 .

MOREIRA, Marco Antonio. Uma análise crítica do ensino de física. Estudos Avançados, v. 32, n. 94, São Paulo, 2018.

OCDE, Organização para a Cooperação e Desenvolvimento Econômico. Brasil está entre os que menos gastam com ensino primário, mas tem investimento 'europeu' em universidade. Disponível em: https://www.bbc.com/portuguese/brasil-41236052. Acesso em: 9 jun. 2018.

PEREIRA, Érico Felden. et al. O trabalho docente e a qualidade de vida dos professores na educação básica. Florianópolis, 2013.

RIGON, Márcia. Prazer em aprender: O novo jeito da escola. Curitiba: Kairós, 2010. 
SALES, Gilvandenys Leite Sales.; BARBOSA, Maria Núbia. Oficinas de física: Uma proposta para desmitificar o ensino de física e conduzir para uma aprendizagem significativa. Fortaleza, 2005.

SILVA, João Batista. A teoria da aprendizagem significativa de David Ausubel: Uma análise das condições necessárias. Research, Society and Development, v. 9, n. 4. 2020. 